\author{
Marquette University \\ e-Publications@Marquette
}

College of Nursing Faculty Research and

Publications

Nursing, College of

$11-2009$

\title{
A Critical Appraisal of Guidelines for Antenatal Care: Components of Care and Priorities in Prenatal Education
}

\author{
Lisa Hanson \\ Marquette University, lisa.hanson@marquette.edu \\ Leona VandeVusse \\ Marquette University, leona.vandevusse@marquette.edu \\ Joyce Roberts \\ University of Michigan - Ann Arbor \\ Amanda Forristal \\ Carl R. Darnall Army Medical Center
}

Follow this and additional works at: https://epublications.marquette.edu/nursing_fac

Part of the Nursing Commons

\section{Recommended Citation}

Hanson, Lisa; VandeVusse, Leona; Roberts, Joyce; and Forristal, Amanda, "A Critical Appraisal of Guidelines for Antenatal Care: Components of Care and Priorities in Prenatal Education" (2009). College of Nursing Faculty Research and Publications. 498.

https://epublications.marquette.edu/nursing_fac/498 
Marquette University

\section{e-Publications@Marquette}

\section{College of Nursing Faculty Research and Publications/Department of Nursing}

This paper is NOT THE PUBLISHED VERSION; but the author's final, peer-reviewed manuscript.

The published version may be accessed by following the link in the citation below.

Journal of Midwifery \& Women's Health, Vol. 54, No. 6 (2009): 458-468. DOI. This article is (C) Wiley and permission has been granted for this version to appear in ePublications@Marquette. Wiley does not grant permission for this article to be further copied/distributed or hosted elsewhere without the express permission from Wiley.

\section{Contents}

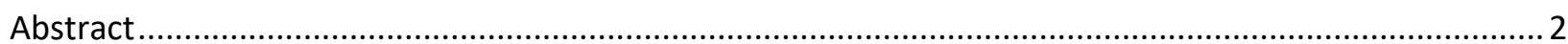

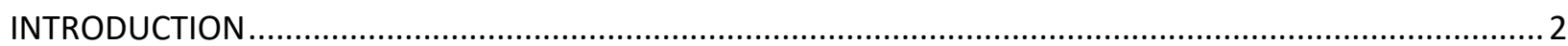

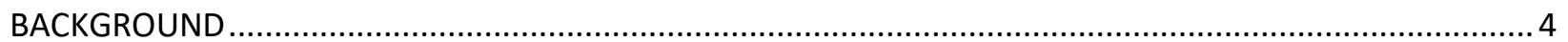

WHAT WOMEN WANT FROM PRENATAL CARE AND EDUCATION ................................................

THEMES IN RECENT PRENATAL CARE GUIDELINES ..............................................................

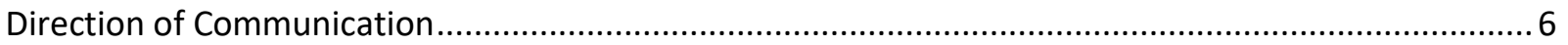

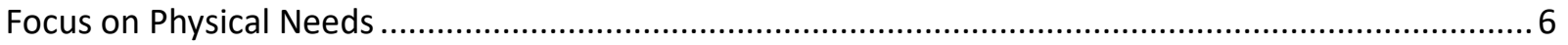

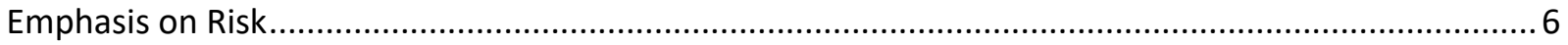

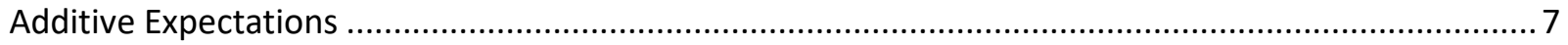

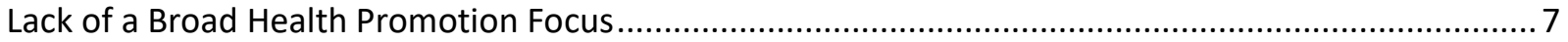

Inconsistent Endorsement of Particular Components of Prenatal Care.......................................... 8

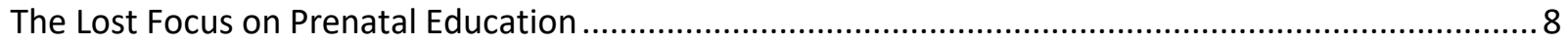

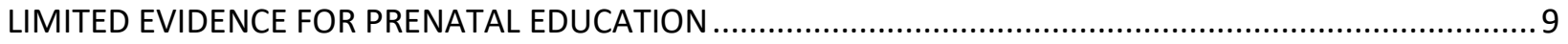

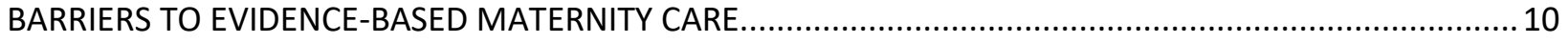

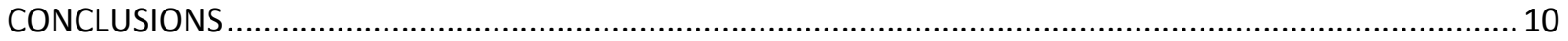

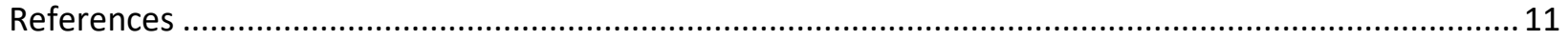

Appendix. Prenatal Care Guideline Topics and Suggested Timing Compared to Timing of Priorities in Prenatal Education. 


\title{
A Critical Appraisal of Guidelines for Antenatal Care: Components of Care and Priorities in Prenatal Education
}

\author{
Lisa Hanson \\ Marquette University, Milwaukee, WI \\ Leona VandeVusse \\ Marquette University, Milwaukee, WI \\ Joyce Roberts \\ University of Michigan, Ann Arbor, MI \\ Amanda Forristal \\ Carl R. Darnall Amy Medical Center, Fort Hood, TX
}

\begin{abstract}
There are a variety of published prenatal care (PNC) guidelines that claim a scientific basis for the information included. Four sets of PNC guidelines published between 2005 and 2009 were examined and critiqued. The recommendations for assessment procedures, laboratory testing, and education/counseling topics were analyzed within and between these guidelines. The PNC components were synthesized to provide an organized, comprehensive appendix that can guide providers of antepartum care. The appendix may be used to locate which guidelines addressed which topics to assist practitioners to identify evidence sources. The suggested timing for introducing and reinforcing specific topics is also presented in the appendix. Although education is often assumed to be a vital component of PNC, it was inconsistently included in the guidelines that were reviewed. Even when education was included, important detail was lacking. Addressing each woman's needs as the first priority was suggested historically and remains relevant in current practice to systematically provide care while maintaining the woman as the central player. More attention to gaps in current research is important for the development of comprehensive prenatal guidelines that contribute effectively to the long-term health and well-being of women, families, and their communities.
\end{abstract}

\section{INTRODUCTION}

There are a variety of published guidelines available for prenatal care (PNC) providers that claim to be evidence-based. Clearly, efforts to practice evidence-based care are encouraged. However, the literature also contains general critiques of evidence-based guidelines, including the following: they outdate quickly with rapidly changing scientific information; ${ }^{1,2}$ they are costly to develop; $;$ they overvalue positivist thinking by reinforcing the value of randomized controlled trials above other methods of knowledge generation; $-\underline{3}$ they overlook the theoretical portion involved in providers' clinical decision making; ${ }^{-3}$ they can have negative ethical consequences if only research-informed judgments can 
be supported, $\underline{3}$ when confirmatory evidence is missing and incomplete in many areas of health care; and they may not account for individual clients' social needs that outweigh the risk and benefits identified by evidence. ${ }^{4}$

The critical evaluation of the scientific basis for clinical practice is essential to provide effective care. However, unique philosophical approaches fostered by different disciplines can result in alternative provisions of care. This is highlighted when comparing definitions of evidence-based care. Sackett et al. -5 proposed the following definition of evidence-based medicine: "Evidence based medicine is the conscientious, explicit, and judicious use of current best evidence in making decisions about the care of individual patients. The practice of evidence based medicine means integrating individual clinical expertise with the best available external clinical evidence from systematic research."

Alternatively, in the definition of evidence-based nursing practice, the evidence is integrated with the practitioner's expertise and the patient's values and preferences..$^{3}$

PNC guidelines that exclusively examine the scientific evidence without considering the values and preferences of each woman may place the evidence ahead of the needs of the women being served. Kennedy et al. ${ }^{4}$ recently identified this as a challenge in evidence-based PNC.

The purpose of this article is to identify and critique the PNC guidelines published within the past 5 years by five organizational groups. They are, in descending chronologic order of publication, by the US Veterans Health Administration, Department of Veteran Affairs, and Health Affairs, Department of

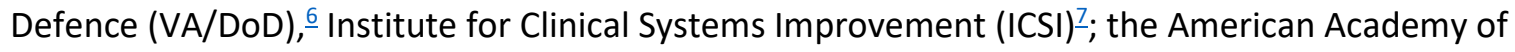
Pediatrics and the American College of Obstetricians and Gynecologists (AAP/ACOG) $\stackrel{8}{\text {; }}$ and the American Academy of Family Physicians (AAFP). $9 \underline{10}$ Key aspects about each of the four guidelines are summarized in Table 1. In addition to critiquing the guidelines, we provide a comprehensive Appendix that includes suggested timing for many topics that were derived from the four guidelines. Educational topics missing in the current guidelines are added as suggestions to facilitate the future provision of comprehensive PNC that includes women's needs and desires.

Table 1. Comparison of Four Antenatal Care Practice Guidelines

\begin{tabular}{|c|c|c|c|}
\hline $\begin{array}{l}\text { Corporate Author, Title, } \\
\text { Publication Date }\end{array}$ & Quality of Evidence & Length & Comments \\
\hline $\begin{array}{l}\text { US Veterans Health } \\
\text { Administration, Department of } \\
\text { Veterans Affairs, and Health } \\
\text { Affairs, Department of } \\
\text { Defense, } 6 \text { Clinical Practice } \\
\text { Guideline: Management of } \\
\text { Pregnancy, } 2009\end{array}$ & $\begin{array}{l}\text { - Five levels } \\
\text { - Provides many cross- } \\
\text { references to evidence base } \\
\text { in literature }\end{array}$ & $\begin{array}{l}162 \text { pages, Internet } \\
\text { accessible } \\
\text { - Includes preconception } \\
\text { details }\end{array}$ & $\begin{array}{l}\text { - Summary, indicates } \\
\text { timing of components to } \\
\text { be included at every visit } \\
\text { or specific visits } \\
\text { - Counseling issues lack } \\
\text { specifics (e.g., } \\
\text { discomforts of pregnancy) }\end{array}$ \\
\hline $\begin{array}{l}\text { Institute for Clinical Systems } \\
\text { Improvement, } \underline{7} \text { Routine } \\
\text { Prenatal Care, } 2008\end{array}$ & $\begin{array}{l}\text { - Seven levels } \\
\text { - Extensive bibliography } \\
\text { provides evidence for the } \\
\text { topics }\end{array}$ & 89 pages, Internet accessible & $\begin{array}{l}\text { - Organized according to } \\
40 \text { topics } \\
\text { - Provides two-page } \\
\text { summary, indicating } \\
\text { timing of components to } \\
\text { be included at each visit }\end{array}$ \\
\hline
\end{tabular}




\begin{tabular}{|c|c|c|c|}
\hline & $\begin{array}{l}\text { - Includes preconception } \\
\text { details }\end{array}$ & & $\begin{array}{l}\text { - Cross-references to } \\
\text { evidence base in } \\
\text { literature } \\
\text { - Provides suggested } \\
\text { resources, including eight } \\
\text { appendices of various } \\
\text { assessment tools }\end{array}$ \\
\hline $\begin{array}{l}\text { American Academy of } \\
\text { Pediatrics and American } \\
\text { College of Obstetricians and } \\
\text { Gynecologists, } 8 \text { Guidelines for } \\
\text { Perinatal Care (6th ed), } 2007\end{array}$ & $\begin{array}{l}\text { - General statement about } \\
\text { incorporating evidence, but } \\
\text { lacks specifics } \\
\text { - Begins with 1st trimester, } \\
\text { not preconception period }\end{array}$ & $\begin{array}{l}\text { Antepartum chapter is } 54 \\
\text { pages }\end{array}$ & $\begin{array}{l}\text { - Most of book focuses } \\
\text { on inpatient, inter- } \\
\text { hospital, and neonatal } \\
\text { care } \\
\text { - General prenatal } \\
\text { education is only briefly } \\
\text { covered } \\
\text { - Psychosocial supports } \\
\text { and parenting education } \\
\text { identified as important, } \\
\text { but this content is limited } \\
\text { - Recommendations lack } \\
\text { specific references }\end{array}$ \\
\hline $\begin{array}{l}\text { American Academy of Family } \\
\text { Physicians, } \underline{9}, 10 \text { Evidence- } \\
\text { based prenatal care, Part 1: } \\
\text { General prenatal care and } \\
\text { counseling and Part 2: Third- } \\
\text { trimester care and prevention } \\
\text { of infectious diseases, } 2005\end{array}$ & $\begin{array}{l}\text { - Three levels } \\
\text { - Extensive bibliography with } \\
\text { specific references for } \\
\text { recommendations } \\
\text { - Begins with 1st trimester, } \\
\text { not preconception period }\end{array}$ & $\begin{array}{l}16 \text { pages total in two journal } \\
\text { issues }\end{array}$ & $\begin{array}{l}\text { - Provides five separate } \\
\text { tables in part } 1 \text { within } \\
\text { which the evidence for } \\
\text { each topic is rated } \\
\text { - Includes cross- } \\
\text { references to evidence } \\
\text { base in literature } \\
\text { - Counseling issues lack } \\
\text { specifics (e.g., } \\
\text { discomforts of pregnancy) }\end{array}$ \\
\hline
\end{tabular}

\section{BACKGROUND}

The landmark document, Caring for Our Future: The Content of Prenatal Care, $\stackrel{11}{\underline{1}}$ was published in 1989 with the goal of establishing evidence for clinical practice and research concerning PNC. $\underline{12}$ The recommendations contained were consensus-based and resulted in six themes: (1) early and continuing risk assessment; (2) health promotion, including the preconception visit; (3) medical and psychosocial interventions; (4) standard documentation; (5) expanding objectives to include the health of the childbearing family through the year following birth; and (6) recommendations for further research. 11

The expert panel that authored the document criticized the fact that in 1986, the United States was tied for seventeenth place in infant mortality internationally, with more than 10.4 deaths per 1000 live births. $\underline{11}$ Unfortunately, more than 20 years later in 2008, US maternal-child health outcomes worsened; by 2008 , the US was ranked twentyninth in infant mortality. $\frac{13}{}$ In fact, for vulnerable families, the inequities in perinatal health outcomes have further deteriorated. $\underline{\underline{13}}$

Infant mortality is multifactorial and disproportionately impacts minority groups with health inequities. The 1989 document identified the evidence base for care practices at that time, but infant mortality in the United States has not decreased since these guidelines were implemented. $\underline{\underline{14}}$ In fact, the 
expectations of PNC as a venue for improving perinatal outcomes have not been realized. $\underline{15}$ Gregory et al. $\underline{12}$ stated that the 1989 guideline served as a "benchmark (for) progress in patient-specific and population-based pregnancy outcomes," but the goals were not met. It remains critical to examine the guidelines and expectations from several broad perspectives, including what pregnant women want.

\section{WHAT WOMEN WANT FROM PRENATAL CARE AND EDUCATION}

In an integrative review by Novick, $\underline{\underline{16}}$ women's experiences of PNC were identified across 36 studies. In one of six themes that she derived from the data, Novick described components of PNC that had three subcategories, including "continuity, comprehensiveness, and control." $\underline{16}$ Related to continuity, women preferred a single provider, although they accepted others with previous notification. Regarding comprehensiveness, women valued counseling, education services, and support groups that complemented PNC, but identified that these were not readily available to them. Concerning control, women wanted more collaborative providers who were good listeners and fostered their involvement in making decisions. Novick identified another theme, "receipt of information," in which women wanted to learn about topics such as physiologic and emotional changes, common discomforts during pregnancy, labor and birth planning, and infant care. These are all forms of anticipatory guidance that are largely omitted from the PNC guidelines critiqued in this article.

Camiletti and Alder $\underline{17}$ surveyed 120 women who were up to 16 weeks pregnant about the information that they would like to learn during the first trimester of pregnancy. The questionnaire was based on a list of topics derived from the literature, then reviewed and expanded by clinicians. The majority of the women were employed and expressed significant interest in three of the topics: the effects of pregnancy on the body, coping with pregnancy discomforts, and a rationale for the PNC schedule. Topics omitted on the questionnaire, yet of interest to the women, were environmental concerns, such as exposure to radiation, allergens and fumes, and the use of hot tubs. The researchers concluded that programs that are based on clients' needs and providers' agendas would be superior to provider-only content determinations.

More recently, Armstrong and Pooley $\underline{\underline{18}}$ conducted a qualitative study with semistructured interviews of 13 pregnant women between 24 and 30 years of age. Themes identified included that women: 1) reported needing support from others, including providers-however, this support was lacking when their providers did not offer guidance; 2 ) identified that the Internet and talking with other women were their major information sources; and 3) expressed the need to be acknowledged as part of the team that

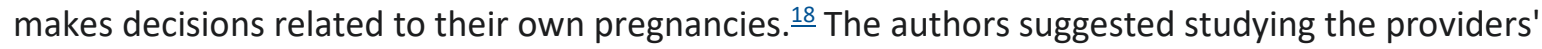
pregnancy-related knowledge level to facilitate women's transitions through this life event, while also listening to each woman for the care and support that would best meet her needs. Kennedy et al., ${ }^{4}$ in their randomized clinical trial of 322 women who were assigned to either individual or group PNC, also affirmed the importance to women of the provision of respectful care and face-to-face time with clinicians in family-friendly environments with reasonable wait times.

The link between the health promotion prenatal education (PNE) topics that are recommended for inclusion in PNC and subsequent health behaviors was shown by Vonderheid et al. $\underline{19}$ They conducted structured interviews with a convenience sample of 159 low-risk African American and Mexican prenatal clinic attendees, three-quarters of whom were on public assistance, unmarried, and had $<12$ years of education. The purpose of the study was to describe the relationship between 22 PNC topics that were recommended as "health promoting" and any associated antepartum health behaviors used by these women. Each woman was given a score that reflected health behaviors related to the health promotion 
items. Examples of the topics included using seatbelts, regular exercise, and smoking cessation. The average number of PNE topics discussed with each woman during the course of pregnancy was 17. Enhanced health behaviors were associated with women's reports of having discussed more health promotion topics with their providers, using fewer harmful substances during the preconception period, and expressing a more optimistic outlook toward pregnancy. Therefore, there is evidence that PNE can influence health behaviors.

What women want in PNC needs to be a priority consideration for providers. Therefore, we began our exploration of guidelines with a focus on PNE. However, the critical appraisal of the published guidelines revealed other emphases.

\section{THEMES IN RECENT PRENATAL CARE GUIDELINES}

As we reviewed the four current prenatal guidelines, six themes found in all four guidelines became apparent: 1 ) the direction of communication between provider and patient; 2 ) a predominant focus on the physical versus psychological needs; 3 ) the increasing attentiveness to risk; 4) additive expectations for PNC; 5) lack of a broad health promotion focus; 6) inconsistent endorsement of component parts of PNC; and 7) lack of attention to PNE. Each theme is explained separately with examples from the PNC guidelines.

\section{Direction of Communication}

One problem noted among the four PNC guidelines is the variation in explanations of the provider's role in relation to the pregnant woman. One example from the ICSI guidelines, ${ }^{7}$ which portrays one-way information to the woman rather than an interactive exchange, states that the provider has "the primary tool used to transmit information to women about their pregnancies...to help reduce modifiable risk factors, and to add to women's satisfaction by increasing their knowledge." The ICSI guidelines $\underline{7}$ include a warning that incomplete maternal advice prenatally was associated with an increase in very low birth weight infants, $\underline{\underline{20}}$ thereby emphasizing the importance of comprehensive information being shared and discussed with women. The VA/DoD $\underline{6}$ guidelines acknowledge the woman as central to care and decision-making by stating the need to "re-emphasize...that she is the most important link in...early diagnosis...and treatment" (p.80), in tandem with more prescriptive language, including "pregnant women should be educated...and should seek" (p.80).

\section{Focus on Physical Needs}

Research related to the components of PNC has focused primarily on physical assessment needs for each individual pregnant woman. This leaves significant gaps in our understanding of women's psychological needs and their wider social contexts, such as the impacts of work, stress, home, nutrition, and broad community concerns. $\underline{\underline{12}}$ As Enkin et al. $\underline{21}$ stated, "The social, psychological, and physical problems experienced by pregnant women are often substantial." However, only the VA/DoD $\underline{6}$ guidelines provide a limited focus on mental health issues, family life/sexuality, and parenting.

\section{Emphasis on Risk}

When psychosocial support does appear in the PNC guidelines, it is often termed "counseling" and has a focus that overemphasizes risk." $\underline{9}$ As Strong stated, $\underline{15}$ "Too often, pregnancy is wrongly perceived as a disease. The 'medicalization' of pregnancy makes prenatal care more costly and...doesn't necessarily improve pregnancy outcomes." A risk orientation detracts from the reality that most women have healthy pregnancies. $\stackrel{22}{ }$ This overemphasis on potential risks can result in missed opportunities to promote long-term health of the woman and her family. $\underline{\underline{12}}, \underline{23}$ 


\section{Additive Expectations}

Because of recent advancements in noninvasive genetic testing, a disproportionate need to focus counseling time on genetics has occurred during early pregnancy. $\stackrel{.12}{*}$ For example, the algorithm for offering and instituting first trimester nuchal translucency screening for Down syndrome requires early entry into PNC, significant time, a variety of health professionals' involvement, and complex individualized decision-making for each pregnant woman. $\underline{12}$ When this screening is available and accepted by the woman, maternal $\alpha$-fetoprotein testing is additionally offered between 15 and 20 weeks' gestation. While a standardized protocol for first-trimester screening has not been established for PNC in the United States, $\underline{12}$ the screening for Down syndrome, neural tube defects, and other structural anomalies extends through the first half of pregnancy for healthy women. Evidence concerning the financial cost of prenatal risk screening is lacking.

It appears that, in general, prenatal screening has at least a small effect in increasing women's feelings

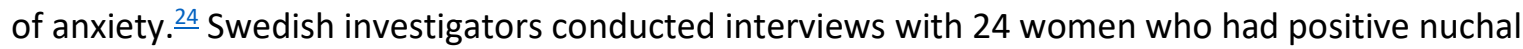
translucency screening findings. Four women who were carrying fetuses with Down syndrome terminated their pregnancies, and the remaining 20 were found to have false-positive results that were associated with significant anxiety reactions and even withdrawal from the pregnancy. $\underline{25}$ Amidst the focus on genetic risk screenings, the broad perspective that can become elusive is that most pregnancies are healthy and produce healthy babies. $\underline{\underline{23}}$

Routine ultrasound use in pregnancy is controversial, yet nearly universal. $\stackrel{7}{-}$ A systematic review of nine trials of routine first-trimester ultrasounds compared to selective scans revealed that first-trimester ultrasounds resulted in the earlier identification of twin pregnancies (twins undiagnosed at 26 weeks; odds ratio, $0.08 ; 95 \%$ confidence interval $[\mathrm{Cl}], 0.04-0.16$ ) and decreased unnecessary postdates pregnancy inductions (odds ratio, $0.61 ; 95 \% \mathrm{Cl}, 0.52-0.72$ ). ${ }^{26}$ However, the practice of routine early pregnancy ultrasound was not associated with improvement in perinatal mortality (odds ratio, 0.86; $95 \%$ $\mathrm{Cl}, 0.67-1.12$ ). Given the prevalence of both nuchal translucency screening and routine ultrasounds, women are commonly experiencing at least two scans during pregnancy to verify mostly healthy pregnancies.

Pregnant women also experience a large number of routine prenatal laboratory tests (see Appendix). Optimally, providers discuss in advance the benefits, risks, and chances of false-positive or falsenegative findings, as well as decision-making options and alternatives once the results are obtained. $\underline{9}$, 22 Because of the significant implications of positive results, documentation of informed consent for genetic and HIV tests are consistently expected in all of the guidelines. $-\underline{6}-\underline{0}$

As the content that must be covered during PNC visits increased over time in order to meet everexpanding expectations, productivity pressures have likely shortened the actual time that providers can spend with pregnant women. ${ }^{27}$ As the need to cover more information during PNC increased, Gregory et al. ${ }^{12}$ proposed that this could require additional support staff, which would further raise costs. For example, specialized genetics counselors offer advantages in consistency and clarity about the testing and subsequent decision-making for pregnant women. However, the PNC provider retains the role of coordinating these complex components of care. Introducing others to women's care, such as genetic counselors during pregnancy to explain the variety of tests, $\frac{12}{2}$ may limit the time available for PNC providers' health promotion focused counseling.

\section{Lack of a Broad Health Promotion Focus}

While the PNC guidelines provide the framework for bringing scientific evidence to prenatal visits, clarity concerning how providers individualize the scientific findings for each woman's reality is lacking. In 
addition, aggregated data about vulnerable women from groups with known disparities and/or unique cultures are also not readily available for practitioners' use.

The guidelines focus almost exclusively on the individual woman's current pregnancy with the end point of care being the birth of the infant or the early postpartum weeks. Long-term health implications are not considered or incorporated into the preventive health opportunities available during prenatal encounters. For example, counseling to avoid obesity is an opportunity to create a healthier nutritional environment for the entire family, well beyond pregnancy and the early postpartum period.

A system of health care based on the reproductive continuum reconceptualized as internatal care has been suggested as an alternative to a discrete preconception visit. ${ }^{23}$ Internatal care begins from the birth of a child and extends through the birth of the next child. $\underline{\underline{23}}$ Using this approach, PNC providers capture opportunities for health promotion before, during, after, and in between pregnancies and across the lifespan for women of child-bearing age. $\frac{12,}{23}$ These internatal visits could include additional health promotion topics, such as infant care, parenting, and strategies for building positive support systems. Women may be able to positively impact the long-term health of themselves and their entire families if health promotion topics were more consistently emphasized. $\underline{\underline{12}}, \underline{23}$

Inconsistent Endorsement of Particular Components of Prenatal Care While health screenings and laboratory testing that necessitate patient counseling have been sequentially added to PNC, various components have been discontinued based on a lack of scientific evidence to support their use. For example, the routine urine dipstick for the presence of proteinuria has been specifically removed in three of the four evidence-based PNC guidelines reviewed. $, \underline{z}, \underline{9}$ Other selected examples where guidelines suggested that routine screenings for low-risk women be discontinued include: clinical pelvimetry ${ }^{6,7}$, ; evaluation for edema ${ }^{6}, \underline{Z}, \underline{9}$; testing for cytomegalovirus, parvovirus, and toxoplasmosis $\underline{\underline{6}, \underline{7}, \underline{10}}$; and screening for bacterial vaginosis for women who have not had a previous preterm birth. $, 7, \underline{10}$ Repeat screening for anemia, syphilis, and HIV are to be reserved for women with high-risk pregnancies. $\frac{6}{}$

There are also inconsistencies among the PNC guidelines. For example, routine instructions for daily fetal movement counts varied significantly. The AAFP guideline presented the evidence against daily fetal movement counts, $\underline{9}$ while AAP/ACOG $\stackrel{8}{8}$ included recommendations in favor of them. The ICSI guidelines ${ }^{7}$ indicated there was no evidence that daily fetal movement counts reduced stillbirths, but suggested continuing the practice. Alternatively, the VA/DoD guidelines $\underline{-}$ provided citations from the 1970 s through the 1980s to support daily fetal movement counts and specified directions for client follow-up if the fetal movements were not of adequate frequency; however, the recommendation failed to stipulate the target frequency.

Another example of inconsistency was repeat testing at 28 to 29 weeks' gestation for isoimmunization in Rh-negative women with low-risk pregnancies. The AAP/ACOG guidelines ${ }^{8}$ contained this suggestion, while the $\mathrm{VA} / \mathrm{DoD}^{-}$recommended against it. Providers of PNC and their clients would benefit from clarity on practices that lack evidence and can be discontinued. Future guidelines need to clarify these contradictory components of PNC to improve efficiency and cost-effectiveness.

\section{The Lost Focus on Prenatal Education}

The related educational components that are considered part of PNC have undergone changes since Roberts ${ }^{28}$ identified priorities in PNE in her classic work published in 1976 . She emphasized four broad priorities of PNE at that time, in descending order of importance: responding to a woman's specific questions; addressing essential health and safety issues; providing anticipatory guidance about pregnancy changes, birth, and infant care; and adding detailed explanations on any topics and 
institutional policies that were beyond the woman's immediate needs. Roberts' $\underline{28}$ insistence that the woman's needs be met first and that information be organized according to gestation, adding to and refining it as pregnancy progressed, remain pertinent today. Her approach relates well to the characteristics of adult learners; specifically their relevancy and goal orientation and their need for practical information. $\underline{29}$ Adults favor education that meets their needs.

In 2008, Sakala and Corry ${ }^{30}$ published an analysis of the evidence about common practices in US maternity care that documented a series of recommendations for improvements. One acknowledged a barrier to evidence-based maternity care that they identified was the "loss of core childbearing knowledge and skills among health pro-fessionals." $\underline{30}$ Their emphasis was on nonintervention in childbirth, but it is logical to note that preparing providers for intrapartum care also requires that they apply the best evidence while caring for pregnant women.

We compared Roberts $\underline{128}$ work to the four current guidelines reviewed and found that all four had glaring omissions regarding PNE. Each of the four sets of guidelines reviewed commented on the educational content of PNC somewhat differently. All of them lacked specifics, depth, and breadth in PNE content. A deliberate, systematic approach to PNE was also found to be absent. For example, the ICSI guidelines ${ }^{7}$ grouped PNE information under the heading "Prenatal and Lifestyle Education" and indicated when various topics should be taught, but offered few details on content. The AAP/ACOG guidelines ${ }^{-}$provided no guidance on timing of PNE unless it involved screening for abnormalities. The AAFP guideline included several well referenced tables on counseling, but gave the impression that all topics would be covered at the first PNC visit, which could overwhelm both providers and pregnant women. While the ICSI guidelines ${ }^{\underline{7}}$ emphasized the inclusion of preterm labor education at every visit from preconception to term, there were large gaps identified in topics pertinent to healthy women.

The lack of guidelines for PNE prompted us to assemble a comprehensive list of PNC topics in the Appendix. It was based on all four sets of guidelines reviewed and PNE with gestational age timing recommendations originally proposed by Roberts ${ }^{28}$ and/or those reported in the guidelines. One column indicates topics addressed in guidelines, where timing was unspecified. The appendix is subdivided into three categorized sections: assessment procedures, education/counseling, and laboratory testing. The goal was to furnish providers with a tool that allows them to access current recommendations for the processes and content of PNC and PNE and the accompanying evidence. At a glance, the Appendix shows which guidelines omitted particular topics, such as specifics about PNE.

\section{LIMITED EVIDENCE FOR PRENATAL EDUCATION}

There is a lack of supportive evidence for PNE. In fact, a recent Cochrane review $\underline{11}$ concluded that highquality evidence was lacking for individual or group PNE offered in structured classes for birth and/or parenting. The authors criticized published research for its usual sampling of educated and economically comfortable participants rather than including those who were medically or socially disadvantaged. In addition, the Cochrane authors found that few of the nine studies examined measured building social support networks, which was an identified omission of content that could potentially have a major negative health impact on patients. The Cochrane researchers ${ }^{31}$ also noted that the programs were typically not based on attendees' needs but on what the educators believed to be important. Although the researchers did not find clear support in favor of structured PNE, they also found no evidence that it was not helpful. However, the study by Vonderheid et al. ${ }^{41}$ did find a relationship between PNC education and subsequent health behaviors. 


\section{BARRIERS TO EVIDENCE-BASED MATERNITY CARE}

Sakala and Corry $\underline{30}$ identified another barrier to evidence-based maternity care: the "limitations of views put forth in media and popular discourse." This point is emphasized in recent data. In the Listening to Mothers // survey, $\underline{32}$ women often reported gathering their information from sources such as television shows on birth and key people in their lives, rather than attending formal childbirth education classes. In the first Listening to Motherssurvey, ${ }^{33}$ which was conducted in 2002, 30\% of expectant parents reported that they had attended childbirth education classes; by the 2006 survey, this number had dropped to only $10 \% . \frac{32}{}$ Clearly, with fewer women attending formal classes, individual education during the course of prenatal visits is increasingly necessary. Questions have arisen about whether maternal health literacy is adequate to promote wellness for childbearing women and their children. $\underline{12}$ Although an "Internet divide" still exists, approximately $70 \%$ of Americans have access to the Internet, and nearly half of all Internet searches are related to topics of health information. ${ }^{34}$ However, disparities in health literacy that limit information available to vulnerable pregnant women have remained, which can have prolonged effects on the well-being of these childrearing families..$\underline{35}$ Some patients have accessed the Internet and searched for health information following a health professional visit $\underline{36}, \underline{37}$ when their questions were not answered. However, only a minority of them ever reported the results of their online searches to their providers for validation..$^{\frac{36}{37}}$ Provider inquiry about the information each pregnant woman seeks would contribute to improved communication and the individualization of her PNC and PNE.

Another barrier to evidence-based maternity care is the "inadequate informed consent processes and women's lack of preparation for making informed decisions." 30 Concepts related to prenatal counseling and decision making have recently been critiqued as being more provider-driven and influenced by professionals' suggestions made to women. ${ }^{22}$ The AAFP guidelines ${ }^{9}$ considered PNE as an important part of PNC that set the groundwork for discussion of issues and choices, acknowledging two-way communication. They also promoted a shared decision-making model, echoed by Gregory et al., $\underline{12}$ who stated "the traditional paradigm of scientific information, patient autonomy, cost and social justice will become increasingly interdependent." With the knowledge that adult learners are both self-directed and autonomous, $\underline{\underline{29}}$ health professionals involved in PNE can optimize educational outcomes when the woman is an active participant in her own learning and decision-making. This reinforces the basic premise that the first priority in PNE is woman-driven $\stackrel{28}{ }$ and would also facilitate learner readiness. $\underline{29}$ Similarly, PNE based on a partnership model allows for the individualization of health education and represents a more contemporary "information age" $\underline{38}$ approach to health care, in which the consumer is more central to the process.

\section{CONCLUSIONS}

Evidence-based PNC guidelines can be informative; however, they also have limitations. Most significantly, PNE is not well addressed and has been insufficiently studied. We have attempted to acknowledge the valuable information and the gaps by critiquing and comparing the content that was included in four recently released PNC guidelines from professional organizations. One of several barriers to implementing the available evidence-based maternity care guidelines is the lack of a womancentered focus. This is contrary to the woman-centered approach advocated by the American College of Nurse-Midwives in their key documents, such as the code of ethics, $\underline{\underline{39}}$ core competencies, $\frac{40}{-}$ philosophy, $\frac{41}{}$ and standards for practice. $\frac{42}{}$

The Appendix is provided to serve as a guide for practitioners to address pertinent topics in the gestational time frames when they are most appropriate. This analysis extends the usefulness of the evidence-based guidelines that are provided by reputable organizations. However, the guidelines have 
failed to identify content as part of a deliberative process of implementation within the social context of PNC delivery. Without the woman as central to the processes of PNC, the guidelines are devoid of their potential for achieving desired outcomes or behavioral changes. The focus, time, and attention given to risk screening to detect relatively uncommon phenomena may interfere with pregnancy information needed by the majority of healthy women. $\frac{22}{5}$ Topics that are important to the safety, comfort, curiosity, health, and well-being of women need to be offered in a systematic manner that assures that important topics are addressed throughout pregnancy. The provision of PNE provides a valuable opportunity for health promotion and risk reduction that may have a lasting impact on the healthy behaviors of the woman and her family. $\underline{12}$ The suggested counseling and education strategies noted in this article can help guide shared decision-making between women and their PNC providers in order to achieve mutually desired outcomes for mothers and their families. ${ }^{30}$ However, more research is clearly needed to elucidate the necessary components of PNC and PNE.

\section{References}

1 Sepers $C$, terMulen R. Regulating health care: The development of guidelines in medical practice and health policy. In terMulen R, Biller-Andorno N, Lenk C, Lie RK, editors. Evidence-based practice in medicine and health care: A discussion of ethical issues. Berlin: Springer-Verlag, 2005:9-16.

2 Tillett J. Developing guidelines and maintaining quality in antenatal care. J Midwifery Womens Health 2009;54:238-40.

3 Ingersoll GL. Evidence-based nursing: What it is and what it isn't. Nurs Outlook 2000;48:151-2.

4 Kennedy HP, Farrell T, Paden R, Hill S, Jolivet R, Willetts J, et al. "I wasn't alone" -A study of group prenatal care in the military. J Midwifery Womens Health 2009;54:176-83.

5 Sackett DL, Rosenberg WM, Gray JA, Haynes RB, Richardson WS. Evidence based medicine: What it is and what it isn't. Br Med J 1996;312:71-2.

6 US Department of Veterans Affairs and the Department of Defense. VA/DoD clinical practice guideline: Management of pregnancy 2009. Available from: http:www.healthquality.va.govpregnancy.asp [Accessed September 10, 2009].

7 Institute for Clinical Systems Improvement Web site. Knowledge resources. Routine prenatal care, 12th ed. Available from: http:www.icsi.orgprenatal care 4prenatal care routine full version 2.html [Accessed September 10, 2009].

8 American Academy of Pediatrics and the American College of Obstetricians and Gynecologists. Guidelines for perinatal care, 6th ed. Washington, DC: American Academy of Pediatrics, 2007.

9 Kirkham C, Harris S, Grzybowski S. Evidence-based prenatal care: Part I. General prenatal care and counseling issues. Am Fam Physician 2005;71:1307-16.

10 Kirkham C, Harris S, Grzybowski S. Evidence-based prenatal care: Part II. Third-trimester care and prevention of infectious diseases. Am Fam Physician 2005;71:1555-60.

11 United States Department of Health and Human Services Expert Panel on the Content of Prenatal Care. Caring for our future: The content of prenatal care. Washington, DC: United States Public Health Service, 1989.

12 Gregory KD, Johnson CT, Johnson TR, Entman SS. The content of prenatal care. Update 2005. Womens Health Issues 2006; 16:198-215.

13 McDorman MF, Mathews TJ. Recent trends in infant mortality in the US NCHS Data Brief, no. 9. Hyattsville, MD: National Center for Health Statistics, 2008.

14 Lu MC, Halfon N. Racial and ethnic disparities in birth outcomes: A life-course perspective.Matern Child Health J 2003;7:13-30. 
15 Strong TH. Expecting trouble: The myth of prenatal care in America. New York: New York University Press, 2000.

16 Novick G. Women's experience of prenatal care: An integrative review. J Midwifery Womens Health 2009;54:226-37.

17 Camiletti YA, Alder R. Learning needs as perceived by women less than or equal to 16 weeks pregnant. Can J Public Health 1999;90:229-32.

18 Armstrong TM, Pooley JA. Being pregnant: A qualitative study of women's lived experience of pregnancy. J Prenat Perinat Psychol Health 2005;20:4-24.

19 Vonderheid SC, Norr KF, Handler AS. Prenatal health promotion content and health behaviors. West J Nurs Res 2007;3:258-76.

20 Sable MR, Herman AA. The relationship between prenatal health behavior advice and low birth weight. Public Health Rep 1997;112:332-9.

21 Enkin M, Keirse MJNC, Neilson J, Crowther C, Duley L, Hodnett E, et al. A guide to effective care in pregnancy and childbirth, 3rd ed. Oxford, UK: Oxford University Press, 2000.

22 Jordan RG, Murphy PA. Risk assessment and risk distortion: Finding the balance. J Midwifery Womens Health 2009;54:191-200.

23 Lu MC, Kotelchuck M, Culhane JF, Hobel CJ, Klerman LV, Thorp JM. Preconception care between pregnancies: The content of internatal care. Matern Child Health J 2006;10(5 suppl):S107-22.

24 Kleinveld JH, Timmermans DR, de Smit DJ, Adér HJ, vad der Wal G, tenKate LP. Does prenatal screening influence anxiety levels of pregnant women? A longitudinal randomised controlled trial.Prenat Diagn 2006;26:354-61.

25 Ohman SG, Saltvedt S, Waldenstrom U, Grunewald C. Pregnant women's responses to information about an increased risk of carrying a baby with Down syndrome. Birth 2006;33:64-73.

26 Neilson JP. Ultrasound for fetal assessment in early pregnancy. Cochrane Database Syst Rev2009;3: 00075320-100000000-00059.

27 King T. Prenatal care for the 21st century: Outside the 20th century box. J Midwifery Womens Health 2009;54:167.

28 Roberts JE. Priorities in prenatal education. J Obstet Gynecol Neonatal Nurs 1976;5:17-20.

29 Knowles MS. The modern practice of adult education. Andragogy vs. pedagogy. Englewood Cliffs, NJ: Prentice Hall/Cambridge, 1980.

30 Sakala C, Corry MP. Evidence-based maternity care: What it is and what it can achieve. New York: The Milbank Memorial Fund, 2008.

31 Gagnon AJ, Sandall J. Individual or group antenatal education for childbirth or parenthood, or both. Cochrane Database Syst Rev 2007;3:CD002869.

32 Declercq ER, Sakala C, Corry MP, Applebaum S. Listening to Mothers II: Report of the second national U.S. survey of women's childbearing experiences. New York: Childbirth Connection, 2006.

33 Declerq ER, Sakala C, Corry MP, Appelbaum S, Risher P. Listening to Mothers: Report of the first national US survey of women's childbearing experiences. New York: Maternity Center Association, 2002.

34 Burns E. U.S. search engine rankings, April 2007. Available from: http:searchenginewatch.com3626021 [Accessed April 14, 2009].

35 Ferguson B. Health literacy and health disparities: The role they play in maternal and child health. Nurs Womens Health 2008;12:286-98.

36 Hesse BW, Nelson DE, Kreps GL, Croyle RT, Arora NK, Rimer BK, et al. Trust and sources of health information: The impact of the internet and its implications for health care providers-findings from the First Health Information National Trends Survey. Arch Intern Med 2005;165:2618-24.

37 Ybarra ML, Suman M. Help seeking behavior and the Internet: A national survey. Int J Med Inform2006;75:29-41. 
38 Smith R. Editorial: The future of healthcare systems. Br Med J 1997;314:1495.

39 American College of Nurse-Midwives. Code of ethics, October 2008. Available from: http:midwife.orgsiteFilesdescriptivecode of ethics 2008.pdf [Accessed May 15, 2009]. 40 American College of Nurse-Midwives. Core competencies for basic midwifery practice, January, 2008. Available from: http:midwife.orgsiteFilesdescriptiveCore Competencies 6 07.pdf [Accessed May 15, 2009].

41 American College of Nurse-Midwives. Philosophy of the American College of NurseMidwives, September 2004. Available from: http:midwife.orgphilosophy.cfm [Accessed May 15, 2009].

42 American College of Nurse-Midwives. Standards for the practice of midwifery, March 2003. Available from: http:midwife.orgsiteFilesdescriptiveStandards for Practice of Midwifery 2003.pdf[Acce ssed May 15, 2009].

Appendix. Prenatal Care Guideline Topics and Suggested Timing Compared to Timing of Priorities in Prenatal Education

\begin{tabular}{|c|c|c|c|c|c|c|}
\hline \multicolumn{6}{|c|}{ Timing Recommendations by Weeks of Gestation ${ }^{\mathrm{a}}$ and Source ${ }^{\mathrm{b}}$} & \multirow[b]{2}{*}{$\begin{array}{l}\text { Timing } \\
\text { unspecified }\end{array}$} \\
\hline Topics & $0 \leq-12$ & $12-24$ & 24-32 & $32-36$ & 36-term & \\
\hline \multicolumn{7}{|l|}{ ASSESSMENT PROCEDURES } \\
\hline Cervical examination & & & B & & A, B & \\
\hline Depression screening & $A, B$ & B & $\mathrm{A}$ & & B & \\
\hline $\begin{array}{l}\text { EDC calculation compared to } \\
\text { uterine size }\end{array}$ & $\begin{array}{l}\text { A, C, D, } \\
E\end{array}$ & $\mathrm{C}$ & $\mathrm{C}$ & $\mathrm{C}$ & C & \\
\hline Fetal growth and status & B & $B, E$ & $\mathrm{~B}, \mathrm{E}$ & $\mathrm{E}$ & & C \\
\hline Fetal heart tones & $A, B, C, D$ & $A, B, C, D, E$ & $A, B, C, D$ & $A, B, C, D$ & $A, B, C, D$ & \\
\hline Fetal movement/quickening & & $B, C, D, E$ & $A, B, C, D$ & $A, C, D$ & $A, C, D$ & \\
\hline Fetal presentation & & & $\mathrm{E}$ & & $A, B, D$ & \\
\hline Fundal height measurement & $A, C, D$ & $A, B, C, D$ & $A, B, C, D$ & $A, B, C, D$ & $A, B, C, D$ & \\
\hline Hypertensive disorder screening & $A, B, C, D$ & $A, B, C, D$ & $A, B, C, D$ & $A, B, C, D$ & $A, B, C, D$ & \\
\hline Intimate partner violence & $A, B$ & & $A, B$ & A & & $C, D$ \\
\hline $\begin{array}{l}\text { NST, BPP, Doppler flow if } \\
\text { indicated }\end{array}$ & & $E$ & & & C & \\
\hline RhoGAM/antepartum & & B & $A, B$ & & $C, D$ & \\
\hline Risk identification/assessment & $A, B$ & B & B & B & B & $C, D$ \\
\hline
\end{tabular}




\begin{tabular}{|c|c|c|c|c|c|c|}
\hline $\begin{array}{l}\text { Stripping of membranes } \geq 38 \\
\text { weeks }\end{array}$ & & & & $A, B, D$ & & \\
\hline Tuberculosis testing & $\mathrm{A}$ & & & & & \\
\hline \multicolumn{7}{|l|}{ Vaccines } \\
\hline - Diphtheria & A & & & & & \\
\hline - Hepatitis B & $A, B$ & & & & & C \\
\hline - Influenza & $A, B, D$ & $A, D$ & $A, D$ & $A, D$ & $A, D$ & $\mathrm{C}$ \\
\hline - Tetanus & $A, B$ & & & & & $\mathrm{C}$ \\
\hline Weight gain & $A, B, C, D$ & $A, B, C, D, E$ & $A, B, C, D$ & $A, B, C, D$ & $A, B, C, D$ & \\
\hline \multicolumn{7}{|l|}{ EDUCATION/COUNSELING } \\
\hline Birth setting information/tour & & & & $\mathrm{E}$ & $\mathrm{C}$ & \\
\hline \multicolumn{7}{|l|}{ Cessation of harmful substances } \\
\hline - Alcohol & $A, D$ & & & & & $\mathrm{~B}, \mathrm{C}$ \\
\hline - Drugs & $A, D$ & & & & & $\mathrm{~B}, \mathrm{C}$ \\
\hline - Teratogens & $\mathrm{D}$ & & & & & $A, B, C$ \\
\hline - Tobacco & $A, D$ & & & & & $\mathrm{~B}, \mathrm{C}$ \\
\hline Circumcision decision making & & & & & & C \\
\hline Danger signs & $\mathrm{B}, \mathrm{E}$ & & $\mathrm{E}$ & $B, E$ & $D, E$ & C \\
\hline Dental care & $\mathrm{A}, \mathrm{E}$ & & & & & $\mathrm{B}, \mathrm{C}$ \\
\hline Employment or school plans & $\mathrm{D}$ & E & B & & & $\mathrm{C}$ \\
\hline Exercise/activity & $A, B, D$ & $\mathrm{~A}$ & $\mathrm{~A}$ & $A, E$ & $\mathrm{~A}$ & $\mathrm{C}$ \\
\hline Family planning/postpartum & & & $\mathrm{A}$ & $\mathrm{B}, \mathrm{E}$ & $\mathrm{C}$ & \\
\hline Genetics counseling as needed & $\mathrm{D}$ & & & & & $\mathrm{B}, \mathrm{C}$ \\
\hline Hair treatment & $\mathrm{D}$ & & & & & \\
\hline Hot tub/sauna use & $\mathrm{D}$ & & & & & $\mathrm{C}$ \\
\hline \multicolumn{7}{|l|}{ Infant feeding } \\
\hline - Breastfeeding education & $A, B, D$ & $A, E$ & $A, E$ & $\mathrm{~A}$ & $\mathrm{~A}$ & $\mathrm{C}$ \\
\hline - Decision making & & $\mathrm{E}$ & $\mathrm{E}$ & & & $\mathrm{D}$ \\
\hline - Formula feeding education & & $\mathrm{E}$ & & & & \\
\hline Labor preparation & & & & & & \\
\hline
\end{tabular}




\begin{tabular}{|c|c|c|c|c|c|c|}
\hline - Analgesia and anesthesia & & & & & $\mathrm{D}$ & \\
\hline - Birth planning/preparation & & & $\mathrm{B}$ & $B, D$ & & \\
\hline - Childbirth class attendance & $\mathrm{B}$ & & $\mathrm{E}$ & $\mathrm{E}$ & $\mathrm{C}, \mathrm{D}$ & \\
\hline - Involvement of significant other & & B & & & $\mathrm{D}$ & C \\
\hline $\begin{array}{l}\text { - Labor signs/symptoms/when to } \\
\text { call provider }\end{array}$ & & & $\mathrm{E}$ & $B, D, E$ & C & \\
\hline - Plan for care of other children & & & $\mathrm{E}$ & & $C, D$ & \\
\hline - Relaxation techniques & & & $\mathrm{E}$ & $\mathrm{E}$ & C & \\
\hline \multicolumn{7}{|l|}{ Musculoskeletal discomforts } \\
\hline - Back pain & & $\mathrm{E}$ & $\mathrm{E}$ & $\mathrm{E}$ & & \\
\hline - Leg ache/cramping/varicosities & $\mathrm{E}$ & $\mathrm{E}$ & $\mathrm{E}$ & & & \\
\hline - Round ligament pain & & $\mathrm{E}$ & $\mathrm{E}$ & $\mathrm{E}$ & & \\
\hline \multicolumn{7}{|l|}{ - Sciatica ${ }^{d}$} \\
\hline Nausea \& vomiting & $\mathrm{B}, \mathrm{E}$ & & & & & C \\
\hline \multicolumn{7}{|l|}{ Nutrition } \\
\hline - Balanced diet & B & $\mathrm{E}$ & & & & $C, D$ \\
\hline - Body Mass Index calculation & $A, B$ & & & & $\mathrm{C}, \mathrm{D}$ & \\
\hline - Folic acid & $A, B, D$ & & & & C & \\
\hline - Food safety & $\mathrm{B}$ & & & & C, D & \\
\hline - Special nutritional needs & & E & & & & \\
\hline - Supplements & $A, B, D, E$ & & A & & & C \\
\hline $\begin{array}{l}\text { Orientation to } \\
\text { provider/practice/prenatal care } \\
\text { processes }\end{array}$ & $B, D, E$ & & & & & C \\
\hline Over the counter medications & $\mathrm{D}, \mathrm{E}$ & & & & & C \\
\hline Pediatric provider selection & & & B & & C & \\
\hline Personal hygiene & & & $\mathrm{E}$ & & & \\
\hline - Body mechanics & & & $\mathrm{E}$ & $\mathrm{E}$ & & \\
\hline - Breast care \& supportive bra & & $\mathrm{E}$ & $\mathrm{E}$ & & & \\
\hline - Comfortable clothing & & $\mathrm{E}$ & $\mathrm{E}$ & & & \\
\hline
\end{tabular}




\begin{tabular}{|c|c|c|c|c|c|c|}
\hline $\begin{array}{l}\text { Physiologic changes/pregnancy } \\
\text { discomforts }\end{array}$ & $\mathrm{B}, \mathrm{E}$ & B & $\mathrm{B}, \mathrm{E}$ & & B & $\mathrm{D}$ \\
\hline - Breast fullness/tenderness & $\mathrm{E}$ & & & & & \\
\hline - Constipation & & $\mathrm{E}$ & & $\mathrm{E}$ & & \\
\hline - Contractions (Braxton-Hicks) & & & $\mathrm{E}$ & $\mathrm{E}$ & & \\
\hline - Dyspnea/shortness of breath & & & $\mathrm{E}$ & $\mathrm{E}$ & & \\
\hline - Emotional changes/fears & & & $\mathrm{E}$ & & & \\
\hline - Fatigue & $\mathrm{E}$ & & & & & \\
\hline \multicolumn{7}{|l|}{ - Heartburn ${ }^{d}$} \\
\hline - Hemorrhoids & & $\mathrm{E}$ & & & & \\
\hline Postdates management & & & & $A, B, D$ & C & \\
\hline Preconception care & $A, B$ & & & & $\mathrm{C}, \mathrm{D}$ & \\
\hline Preparation for baby & & & $\mathrm{E}$ & $\mathrm{E}$ & $\mathrm{E}$ & \\
\hline - Household assistance & & & $\mathrm{E}$ & & & \\
\hline - Supplies & & & $\mathrm{E}$ & & & \\
\hline Preterm labor education & B & B & $A, B$ & $A, B$ & $\mathrm{C}$ & \\
\hline Rest & & & & $\mathrm{E}$ & & \\
\hline $\begin{array}{l}\text { Review laboratory results with } \\
\text { woman }\end{array}$ & B & & & & & \\
\hline Safety/seatbelts & & & & & $\mathrm{C}$ & \\
\hline Sexuality & $\mathrm{D}$ & & $\mathrm{E}$ & & B & \\
\hline \multicolumn{7}{|l|}{ Supine hypotension $\underline{\text { d }}$} \\
\hline Travel & $\mathrm{D}$ & E & & B & & $\mathrm{C}$ \\
\hline Tubal ligation authorization & & & $\mathrm{E}$ & & & \\
\hline Urinary frequency & $\mathrm{E}$ & & & & & \\
\hline Vaginal discharge & & E & & $\mathrm{E}$ & & \\
\hline VBAC informed consent & $\mathrm{B}$ & & $\mathrm{A}$ & $\mathrm{B}$ & & $\mathrm{C}$ \\
\hline \multirow{2}{*}{\multicolumn{7}{|c|}{$\begin{array}{l}\text { LABORATORY TESTING } \\
\text { Genetics Testing }\end{array}$}} \\
\hline & & & & & & \\
\hline - Disease specific & A & & & & $\mathrm{B}, \mathrm{C}, \mathrm{D}$ & \\
\hline
\end{tabular}




\begin{tabular}{|c|c|c|c|c|c|c|}
\hline - Nuchal translucency screen & $A, B, C, D$ & $\mathrm{C}$ & & & & \\
\hline - Triple/Quad Screen & $A, C$ & $A, B, C, D$ & & & & \\
\hline \multicolumn{7}{|l|}{ Routine } \\
\hline - Antibody Screen & $A, B, C$ & & B & & & $\mathrm{D}$ \\
\hline - Blood Type and Rh & $A, B, C, D$ & & & & & \\
\hline - Chlamydia & $A, B, C, D$ & & & $\mathrm{C}$ & & \\
\hline - Complete blood count & $A, B, C$ & & & & $\mathrm{D}$ & \\
\hline - Gestational diabetes & $A$ & $\mathrm{~B}, \mathrm{C}$ & $A, B, C, D$ & & & \\
\hline - Gonorrhea & $A, B, C, D$ & & & & & \\
\hline - Group B strep & & & $\mathrm{C}$ & $\mathrm{C}$ & $A, B, D$ & \\
\hline - Hemoglobinopathies & $\mathrm{A}$ & & & & & \\
\hline - Hepatitis B surface antigen & $A, B, C, D$ & & & & & \\
\hline • HIV & $A, B, C$ & & & & $\mathrm{D}$ & \\
\hline - Papanicolau smear & $A, B, C, D$ & & & & & \\
\hline - Rubella & $A, B, C$ & & & & $\mathrm{D}$ & \\
\hline - Syphilis & $A, B, C, D$ & & & & & \\
\hline - Tdap booster status & A & & & & & \\
\hline $\begin{array}{l}\text { - Ultrasound, routine (16-20 } \\
\text { weeks) }\end{array}$ & & $A, B, D$ & & & C & \\
\hline - Urinalysis/urine culture & $A, B, C$ & & & & $\mathrm{D}$ & \\
\hline - Varicella & $A, B, C$ & $\mathrm{D}$ & & & & \\
\hline \multicolumn{7}{|l|}{ Selective } \\
\hline - Hepatitis C testing & & & & & $\mathrm{D}$ & \\
\hline - Herpes antibodies & $A$ & & & & $C, D$ & \\
\hline
\end{tabular}

$\mathrm{BPP}=$ biophysical profile; $\mathrm{EDC}=$ Estimated date of confinement; $\mathrm{NST}=$ nonstress test VBAC = vaginal birth after cesarean.

aSeveral prenatal visits can occur within each time frame specified, necessitating repeating some of the topics.

${ }^{b}$ The letters of the body of the table refer to the publication source. $A=$ Veterans Health Administration, Department of Veterans Affairs, and Health Affairs, Department of Defense [VA/DoD] $\underline{6}$; $B=$ Institute for Clinical Systems Improvement [ISCI] $;$; C = American Academy of Pediatrics and the American College of 
Obstetricians and Gynecologists [AAP/ACOG] ; D = American Academy of Family Practice [AAFP] by Kirkham et al. $\underline{9}, \underline{10}$; and $\mathrm{E}=$ Priorities in Prenatal Education by Roberts. $\underline{28}$

'Zero weeks refers to preconception care topics, covered in two of the guidelines [VA/DoD $\underline{6}$ and ISCI $\underline{\text { ] }}$.

${ }^{\mathrm{d}}$ Topic that was not included in any of the guidelines. 